\title{
Activated carbon-plasticised agarose composite films for the adsorption of thiol as a model of wound malodour
}

Authors: Illsley $\mathrm{MJ}^{1}$, Akhmetova $\mathrm{A}^{2}$, Bowyer $\mathrm{C}^{3}$, Nurgozhin $\mathrm{T}^{2}$, Mikhalovsky SV ${ }^{1}$, Farrer $\mathrm{J}^{3}$, Dubruel $\mathrm{P}^{4}$, Allan IU ${ }^{1}$

\section{Author Affiliations and addresses:}

1. School of Pharmacy and Biomolecular Sciences, University of Brighton, Brighton, BN2 4GJ, United Kingdom

2. Laboratory of Experimental and Clinical Pharmacology and Pharmacy, National Laboratory Astana, Nazarbayev University, Astana, Kazakhstan

3. Enterprise \& Innovation, Faculty of Creative and Cultural Industries, University of Portsmouth, Winston Churchill Avenue, Portsmouth, PO1 2UP, United Kingdom

4. Polymer Chemistry \& Biomaterials Group, Ghent University, Krijgslaan 281 (S4-bis), B-9000, Ghent, Belgium

\section{Graphical abstract}

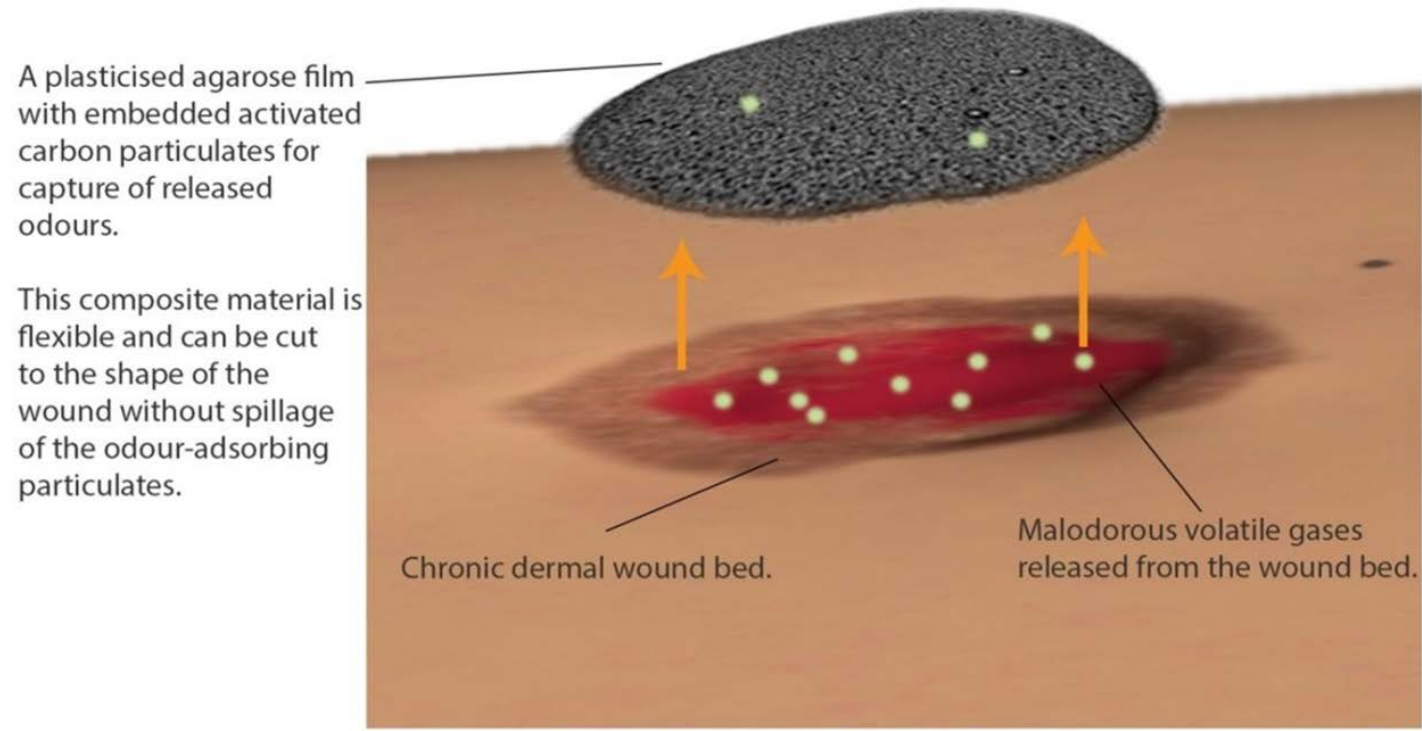

\section{$\underline{\text { Abstract }}$}

Conditions such as diabetes, cardiovascular disease and long-term immobilisation can precipitate the development of chronic dermal ulcers. Such wounds are associated with inflammation and bacterial contamination which in turn can lead to the liberation of offensive odours that cause patient embarrassment and, in some instances, social isolation. Activated carbon-containing dressings have been used to manage the odours from such wounds. However, these can be bulky and can become fouled by wound exudate. Agarose is a natural polysaccharide derived from seaweed that forms 
brittle free-standing films that can be made pliable by addition of a plasticiser. In this study, activated carbon-containing plasticised agarose films were evaluated for their ability to sequester thiol-containing molecules from solution and the gaseous phase. The water vapour transmission rate was also evaluated to determine the potential breathability of these films should they be considered for application to the skin. It was found that the adsorption of thiols was directly proportional to the activated carbon content of the films. Water vapour was found to pass relatively freely through the films indicating that sweat-induced tissue maceration would be unlikely to occur if applied clinically. In conclusion, activated carbon-containing plasticised agarose films have some potential in the sequestration of malodourous molecules such as those liberated from chronic dermal wounds.

\section{Introduction}

My journey toward joining the biomaterials community has been somewhat circuitous. I graduated from Glasgow University with an honours degree in microbiology and then subsequently undertook an MSc in Biology of Water Resource Management at Napier University. For a while I thought the latter was something of a waste of time, but now find myself working with marine-derived biomaterials. I then undertook a PhD at UCL where I investigated the antimicrobial properties of a bioactive glass used for periodontal bone repair. This biomaterial has now found its way into a wellknown brand of toothpaste for sensitive teeth! I later joined the University of Brighton where I continued with microbiology research but also developed an interest in biomaterials, including cryogels for dermal tissue regeneration. To evaluate these materials necessitated developing an expertise in cell culture techniques. My first project as PI was an EU Interreg 2 Seas project called Biocare marine. This focused my research towards evaluating natural polymers as the basis for new biomaterials. A new project, DERMA, builds on this work and specifically focuses on developing dressings for chronic dermal wound management. It is in this area that I wish to consolidate my research - bringing my expertise in microbiology, biomaterials and cell culture to focus on a specific and growing problem as the life expectancy of the population increases. I would like to consolidate and expand my network of collaborators in Europe and also seek partnerships with industry to ultimately improve the wellbeing of patients.

Chronic wounds are those that do not heal within 12 weeks and include decubitus ulcers (bedsores or pressure sores) and venous, ischaemic or traumatic leg ulcers [1]. Age-related conditions including long-term immobilisation, fungating tumours, diabetes, cardiovascular disease and arthritis are all associated with the development of such chronic dermal ulcers [2-6]. The treatment of such ulcers has been estimated to account for $4 \%$ of the UK healthcare budget [7].

Non-healing wounds are composed of devitalised tissue in various stages of degradation and generally harbour a population of contaminating or infecting bacteria. These factors are responsible for the liberation of malodorous gases from the wound bed. The most prevalent and readily recognisable wound odour of bacterial origin is that produced by Pseudomonas aeruginosa. This organism is one of the principle pathogens responsible for nosocomial infections, and produces several volatile compounds (VCs) including aliphatic alcohols, ketones, dimethylpolysulphides and alkenes [8]. Most notable of these is 2-aminoacetophenone which is responsible for the characteristic grape-like odour accompanying $P$. aeruginosa infection [9]. Suppurating infections with this bacterium are also associated with a blue-green colouration caused by the presence of 
bacterially-produced pyocyanin. Other bacterial genera associated with problematic wound malodour include Bacteroides, Clostridium, Proteus and Klebsiella [10, 11].

Tissue destruction caused by bacteria, or by excessive inflammation, will also liberate a proportion of thiol-containing volatile sulphur compounds (VSCs) $[12,13]$. Such malodorous wounds can lead to patient embarrassment, depression and social isolation [14, 15].

Agarose is a linear polysaccharide derived from seaweed that forms thermo-reversible gels. These gels form free-standing transparent films upon drying. Agarose is natural, renewable, biodegradable and non-toxic. Agarose films are very brittle and cannot withstand handling or other mechanical stresses without the addition of a plasticising agent. Recently, a novel plasticised agarose was described which utilises a non-toxic ionic liquid, composed of choline chloride and urea, as a plasticising agent [16]. PA has the advantage of being pliable, non-adherent to dermal cells, breathable and biodegradable.

Activated carbon (AC) has well known odour-adsorbing properties enabled by its porous structure which confers an extremely high surface area to volume ratio for the adherence of small molecules [17]. VCs have been shown to adhere to AC [18], and indeed AC-containing wound dressings are available to clinicians [19]. In this study, we sought to produce PA films with embedded AC particulates and evaluate the odour-adsorbing performance of these. 


\section{Materials and Methods}

\section{Preparation of activated carbon (AC) containing plasticised agarose (PA) films.}

A eutectic-based ionic solution was prepared as the plasticising component according to the method published by Shamsuri \& Daik (2012). Solid choline chloride and urea were mixed in a molar ratio of $1: 2$, respectively and heated at $100 \circ \mathrm{C}$ until a clear ionic liquid had formed.

To prepare the PA films; a $2.86 \mathrm{ml}$ solution of the ionic liquid was diluted to $100 \mathrm{ml}$ with $\mathrm{dH}_{2} \mathrm{O}$, and $2.86 \mathrm{~g}$ agarose added to this solution followed by heating at $98^{\circ} \mathrm{C}$ in a water bath for at least 2 hours. To prepare films, the hot PA solutions were poured into PTFE-coated trays and allowed to set at RT. The gels were then dried for $24 \mathrm{~h}$ in an oven at $60^{\circ} \mathrm{C}$. AC-containing films were prepared in the same way with AC particles (Norit A SUPRA EUR) added to ionic liquid-agarose solutions prior to heating to give wet gel weight concentrations of $0.0625,0.125,0.25$ and $0.5 \% \mathrm{w} / \mathrm{v}$. These gels were then dried as above.

\section{Water vapour transmission across AC-PA films}

$100 \mathrm{~mL}$ weighed volumes of distilled water were placed in vapometer permeability cups (Tendring Pacific) which encompass brass pots sealed with rubber ' $O$ ' rings and a PTFE ring. The sample films were held between the rubber rings and the brass lid tightened above the protective PTFE (which stops tearing of the underlying sample due to contortion of the rubber rings). The vessels were weighed before and after addition of the water and films. These were then incubated for exactly 24 $h$ at $37^{\circ} \mathrm{C}$ in a warm room in the same position for each test before being re-weighed.

\section{Thiol adsorption by AC-PA films}

$5 \mathrm{~mm}$ diameter punched circles of the relevant films were placed into a 96-well plate containing cysteine hydrochloride monohydrate at a concentration of $10 \mathrm{mM}$. Following a $2 \mathrm{hr}$ incubation, $100 \mu \mathrm{L}$ of the solution was added to Ellman's reagent (final DTNB concentration $0.07 \mathrm{mg} / \mathrm{mL}$ diluted in a reaction buffer of $0.1 \mathrm{M}$ sodium phosphate and $1 \mathrm{mM}$ EDTA, at $\mathrm{pH} 8.0$ ), the samples were left for 15 min to develop colour and the absorbance was measured on a UV-Vis spectrophotometer at $415 \mathrm{~nm}$ which is the peak absorption wavelength of the Ellman's reagent when reacted with thiol. The measured absorbance was directly proportional to the free thiol content of the solution and determined against a standard curve of $0-15 \mathrm{mM}$ cysteine prepared in the same way and measured at $415 \mathrm{~nm}$.

\section{Thiol transmission through AC-PA films}

As well as measurement of thiol adsorption to the films in in solution, the adsorption of thiol vapour to the films was also measured. The test film was clamped over a reservoir of $100 \mu$ l butanethiol (butyl mercaptan) and the headspace circulated through a solution of Ellman's reagent for up to 2 hours, the resulting colour was determined spectrophotometrically at $415 \mathrm{~nm}$. The concentration of thiol that had reacted with the Ellman's reagent was determined by reference to a standard curve prepared with 0-15 mM cysteine and spectrophotometrically measured at $415 \mathrm{~nm}$. The transfer of thiol through the film was adjusted for time and film thickness, resulting in a measurement of $\mathrm{mM} / \mu \mathrm{m} / \mathrm{h}$. 


\section{Statistical analysis}

All data comparisons were made with one way ANNOVA and post-hoc Tukey analysis at a $95 \%$ confidence interval. A $p$ value of $\leq 0.05$ was considered significant. 


\section{$\underline{\text { Results }}$}

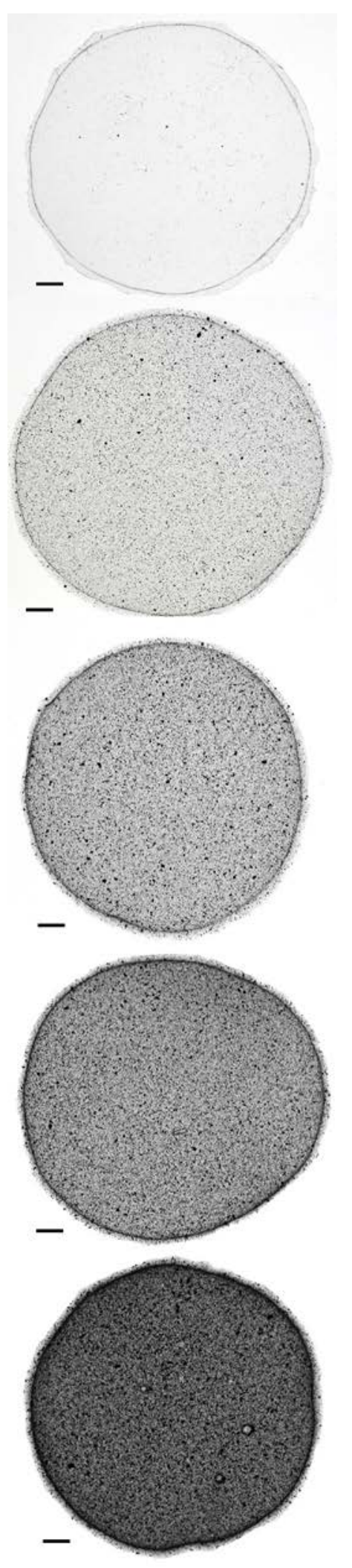

Figure 1 Photographs of representative PA films containing, from top to bottom; $0 \%, 0.0625 \%$, $0.125 \%, 0.25 \%$ and $0.5 \% \mathrm{w} / \mathrm{v}$ AC (pre-drying gel weight). Scale bars represent $2 \mathrm{~mm}$. 
AC-PA films became increasingly dark with increasing AC content (fig. 1). The $0 \%$ AC film was transparent while the $0.5 \% \mathrm{w} / \mathrm{v}$ AC film was opaque. Some shrinkage after drying of the hydrogel formulations was noted, but the resultant films remained flexible and pliable at all AC concentrations. The films are able to be easily cut to a desired shape with the AC still retained.

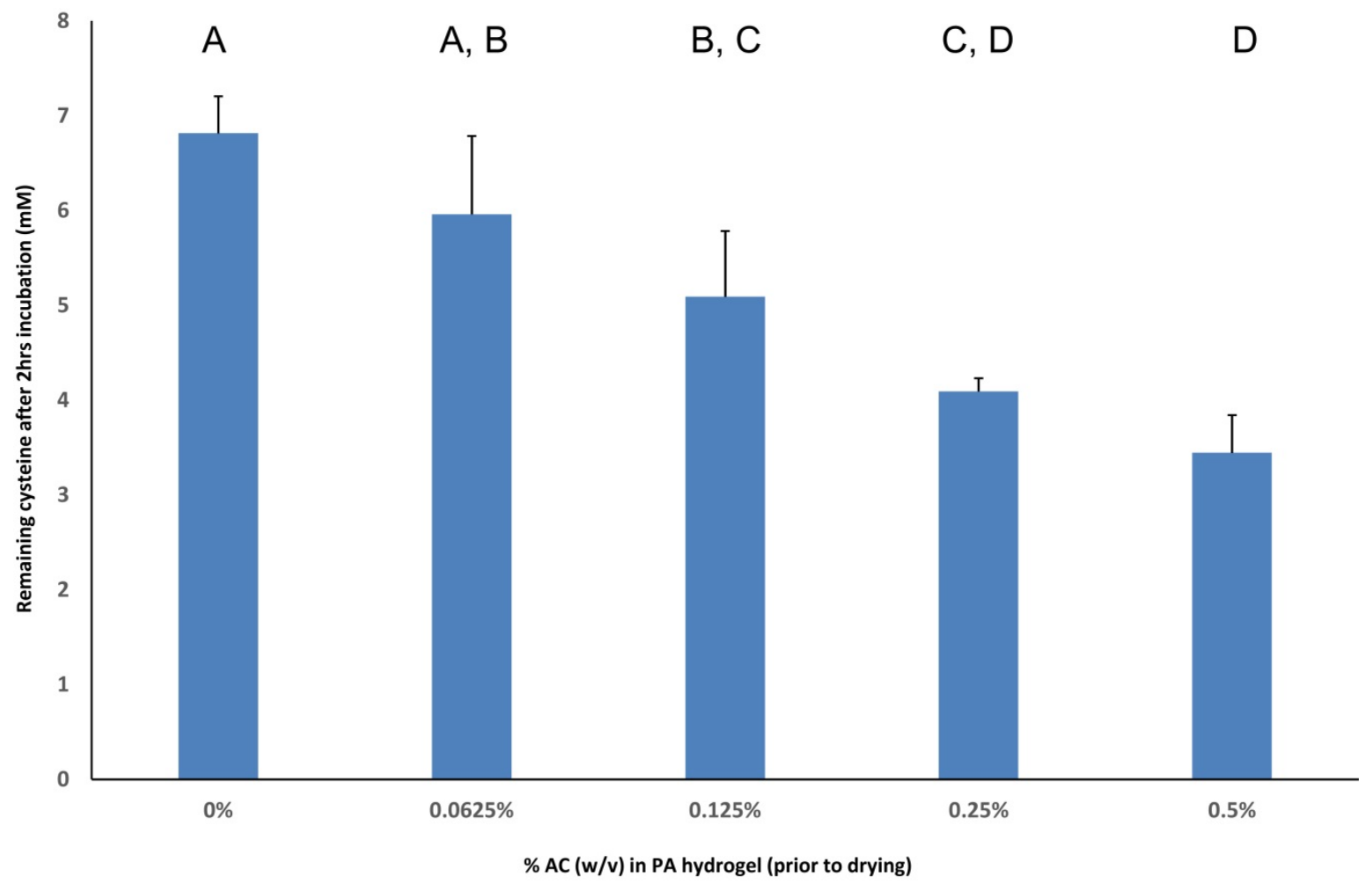

Figure 2 Sequestration of thiol-containing cysteine by $0 \%-0.5 \% \mathrm{w} / \mathrm{v}$ (pre-drying gel weight) AC in PA films after $2 \mathrm{~h}$ incubation. Error bars $=\mathrm{SD}, \mathrm{n}=5$. Means that do not share a letter are significantly different, $p<0.05$.

The ability of the films to remove cysteine from solution was quantified. After $2 \mathrm{~h}$ incubation, the $0 \%$ PA film had sequestered approximately $3.2 \mathrm{mg}$ of the $10 \mathrm{mg}$ of cysteine available. The $0.0625 \%$ formulation did not remove a significantly different amount of thiol compared with the $0 \% \mathrm{AC}$ formulation, however the $0.125 \%$ AC concentration did, with approximately $4.9 \mathrm{mg}$ removed. The $0.25 \%$ and $0.5 \%$ AC films removed 5.9 and $6.6 \mathrm{mg}$ respectively, both significantly different from the $0 \%$ AC control. 


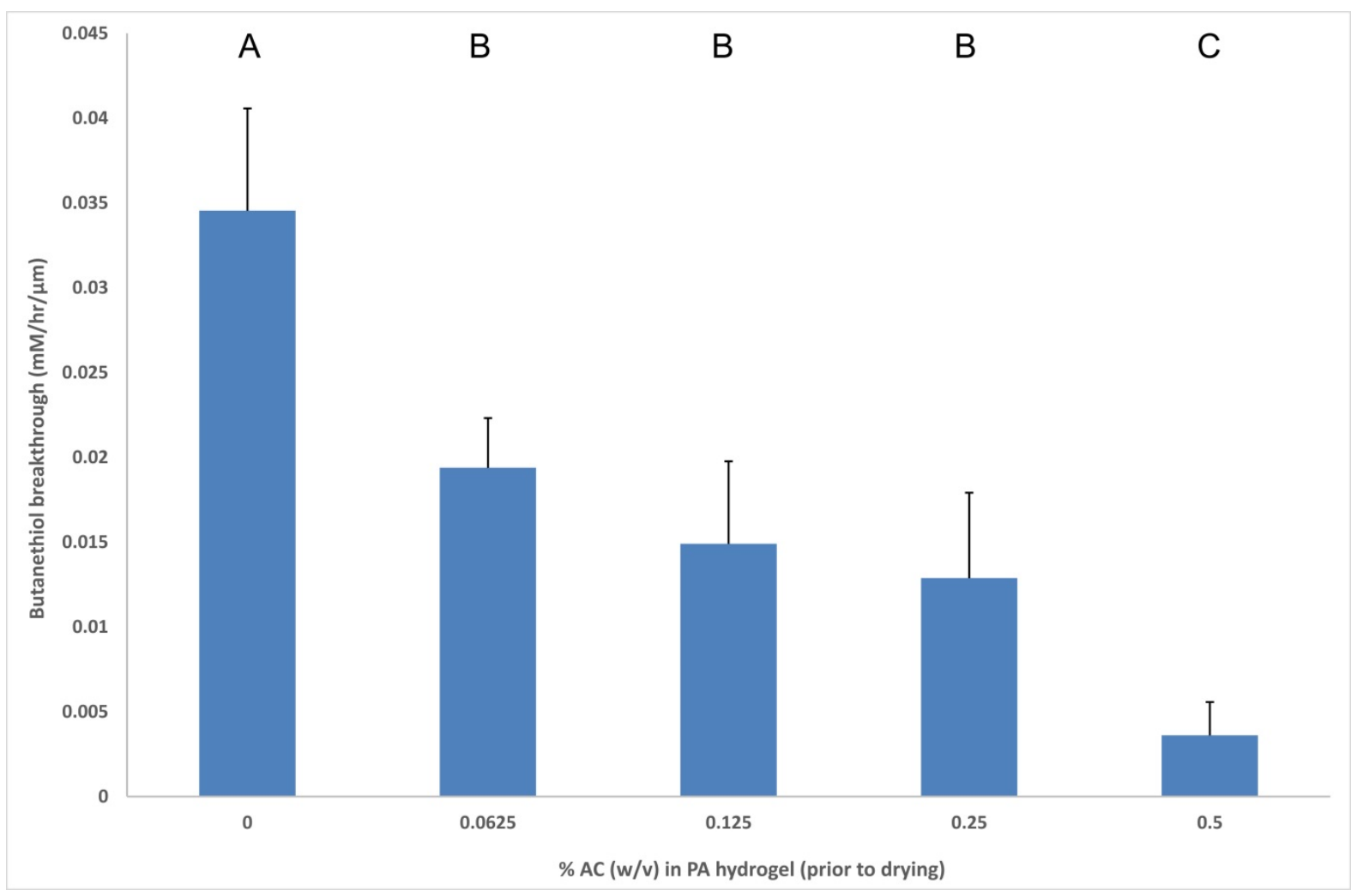

Figure 3 Transfer of volatile butanethiol through the AC-PA films ( $0 \%-0.5 \%$ pre-drying gel weight) adjusted for time and thickness of the films, therefore $m M / \mu m / h$. Error bars $=S D, n=5$. Thiol transmission without films was $75 \mathrm{mM} / \mathrm{h}$. Means that do not share a letter are significantly different, $\mathrm{p}<0.05$.

The ability of the films to sequester malodorous and volatile thiol from the gaseous phase was quantified by monitoring the concentration of thiol in a headspace on the upper side of the films held above a reservoir of thiol solution below. A breakthrough concentration of $0.034 \mathrm{mM} / \mu \mathrm{m} / \mathrm{h}$ for $0 \%$ AC film was measured which was significantly higher than the AC-containing formulations, which had breakthrough concentrations of approximately $0.019,0.015,0.013,0.004 \mathrm{mM} / \mu \mathrm{m} / \mathrm{h}$, for the $0.0625,0.125,0.25$ and $0.5 \%$ AC formulations, respectively. No significant differences were found between the $0.0625,0.125$ and $0.25 \%$ AC formulations, however significantly less thiol broke through the $0.5 \% \mathrm{AC}$ formulation. 


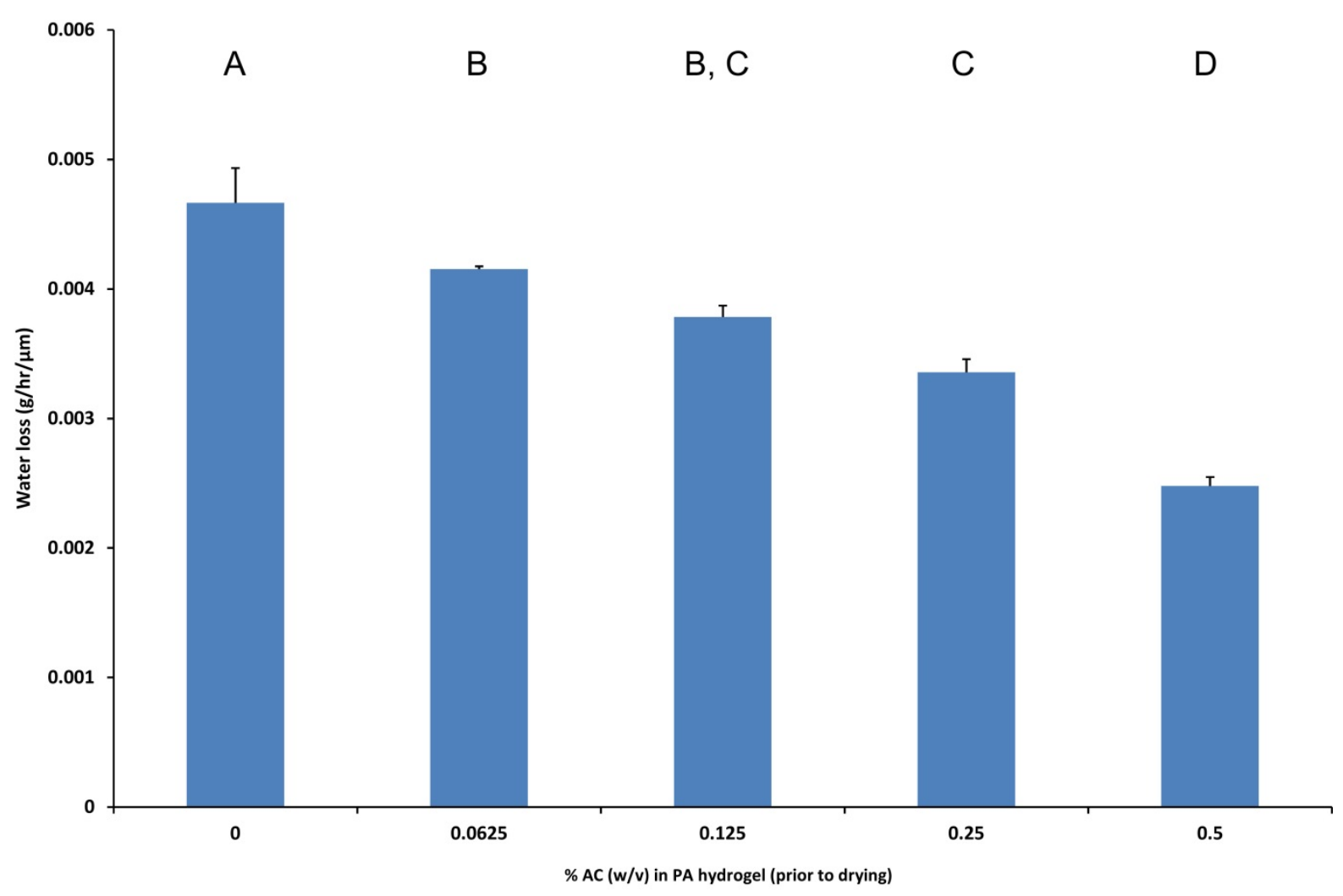

Figure 4 Water vapour transmission through the AC-PA films ( $0 \%-0.5 \% \mathrm{w} / \mathrm{v}$ pre-drying gel weight) expressed in grams per $\mu \mathrm{m}$ per hour. Error bars $=S D, n=3$. The means values that do not share a letter are significantly different, $p<0.05$.

For the WVT test, PA alone allowed water vapour passage at a rate of approximately 0.0047 $\mathrm{g} / \mu \mathrm{m} / \mathrm{hr}$. The addition of $\mathrm{AC}$ significantly decreased the water vapour transmission rate, with rates of $0.0042,0.0038,0.0034 \mathrm{~g} / \mu \mathrm{m} / \mathrm{hr}$ for the $0.0625,0.125,0.25 \% \mathrm{AC}$ formulations, respectively. The $0.5 \% \mathrm{AC}$ formulation caused the greatest reduction to a figure of $0.0025 \mathrm{~g} / \mu \mathrm{m} / \mathrm{hr}$ which was significantly different to the other formulations.

Table 1 Thickness measurements of AC-PA films after drying the hydrogel for $24 \mathrm{~h}$ at $60^{\circ} \mathrm{C}$.

The thickness of the films increased with increasing $A C$ content, with means ranging from 86.52, $97.15,106.30,120.59$ and $149.74 \mu \mathrm{m}$ for the $0,0.0625,0.125,0.25$ and $0.5 \%$ AC formulations. All formulations had statistically different thicknesses.

\begin{tabular}{|l|l|l|l|l|}
\hline $\begin{array}{l}\text { Film \% AC w/v (pre- } \\
\text { drying gel weight) }\end{array}$ & Thickness $(\boldsymbol{\mu m})$ & SD $\mathbf{\pm}$ & $\mathbf{N}$ & Statistical grouping $\mathbf{p}<\mathbf{0 . 0 5}$ \\
\hline 0 & 86.52 & 9.44 & 29 & A \\
\hline 0.0625 & 97.15 & 12.40 & 39 & B \\
\hline 0.125 & 106.30 & 7.41 & 33 & C \\
\hline 0.25 & 120.59 & 9.60 & 34 & D \\
\hline 0.5 & 149.74 & 15.47 & 35 & E \\
\hline
\end{tabular}




\section{$\underline{\text { Discussion }}$}

AC-containing PA films (Fig. 1) were found to adsorb malodorous butanethiol in an AC concentration-dependent manner. Thiol sequestration by AC was achieved in both the liquid (Fig. 2) and vapour phase (Fig. 3). Interestingly, the PA film containing $0 \%$ AC provided a reasonable barrier function alone, but with thiol adsorption significantly increased with the addition of AC. The adsorption capacity of $A C$ in the liquid phase is well known [20]. One disadvantage of direct contact of AC with biological fluids is fouling and a loss of adsorption efficiency [21]. In the context of a wound dressing, contamination of $A C$ with macromolecules from wound fluid would be expected to reduce the odour adsorbing efficiency of $A C$. Moreover, bacteria are known to readily adhere to AC $[22,23]$ where they could act as a reservoir for continuous contamination and infection of the underlying wound, especially as the AC would likely adsorb available nutrients that would then be accessible as a growth medium for bacterial biofilm formation. Thus, we also sought to evaluate the odour capturing efficacy of $A C$ when encapsulated by a relatively biologically inert polymer. This would prevent wound fluid from accumulating on the surface and within the pores of the $A C$, and prevent the passage of bacteria from the wound bed to the AC.

There are few published data concerning adsorption of malodour compounds by AC dressings [24, 25] from the vapour phase.

Currently the British National Formulary [26] describes five malodour adsorbing dressings available to treat patients, and these can be grouped into two categories:

Non-absorbent: Askina Carbosorb, primary or secondary dressing with an absorbent layer of nonwoven viscose-rayon, and an activated charcoal cloth layer, has a limited absorption capacity; Carbopad VC, primary dressing that combines a vapour permeable film and a $100 \%$ activated charcoal cloth, dressings should be changed frequently (one to three times a day); CliniSorb Odour Control Dressing is a secondary non-adherent dressing containing activated carbon cloth, dry to medium exudate;

Absorbent: CarboFLEX, a primary or secondary dressing that has an absorbent wound contact layer (containing Kaltostat and Aquacel) combined with an activated charcoal central pad with smooth water-resistant top layer that should not be cut; Sorbsan Plus Carbon is a primary or secondary dressing for use on wounds with high levels of exudate.

There is no available information in the literature on the absorbance capacity of the dressings described in the national formulary. However, all these dressings contain charcoal cloths that are $85 \%$ to $98 \%$ activated carbon. The novel material described in this paper best fits the non-absorbent category, comprising of a polymer film embedded with powdered activated carbon (Norit A SUPRA EUR, FDA approved for medicinal use) especially developed to adsorb odour. Powdered activated carbon has significantly increased surface area and adsorption capacity when compared with carbon cloth. The used of powdered AC therefore represents an improvement from the currently available dressings. The odour adsorbing portion of the composite film described here contains $100 \%$ AC and the data indicate that there is no loss of function from incorporation into the polymer and it can be cut to fit the shape of a wound without loss of function. 
All the AC-containing films described were found to allow the passage of water vapour (fig 4) and therefore were considered breathable. This is important in the context of their potential use as a wound dressing material. Excessive sweat and wound fluid would accumulate under a dressing that was not breathable, leading to maceration of the underling skin, causing the wound prognosis to worsen.

The literature suggests that normal skin WVT rate is $9 \pm 4.5 \mathrm{~g} / \mathrm{m}^{2} / \mathrm{h}$ and an exposed venous leg ulcer, $78.2 \pm 8.9 \mathrm{~g} / \mathrm{m}^{2} / \mathrm{h}$, [27] while it is clear that dressings facilitate reduced WVT and maintain an optimum healing environment [28]. The WVT data here is adjusted for comparison between thicknesses of prototypes, requiring further modification of the data available in $\mathrm{Wu}$, Fisher et al 1995. This gives us a WVT range for commercially available dressings of $0.33 \mathrm{~g} / \mu \mathrm{m} / \mathrm{h}$ and 0.001 $\mathrm{g} / \mu \mathrm{m} / \mathrm{h}$. The prototype dressing materials described here all had WVT rates within this clinically acceptable range.

The addition of AC to the PA films did significantly increase the thickness of the films at all addition concentrations (Table 1), to maintain comparable data the authors have taken this effect into account. This increase is due to a combination of the additional weight of material left after drying the water from the polymer system and the modest shrinkage that occurs with additional AC. Increasing shrinkage could be due to a surface adsorption effect onto the AC, resulting in the carbons interacting with and retaining water, plasticiser, or the polymer while drying occurs.

This in vitro study utilised model malodorous molecules for assessment of the ability of ACcontaining plastcised agarose films to ameliorate the release of malodours from wounds when used as a dressing. Further testing will be required against a suite of maldorous molecules known to be released from wounds, and ultimately the materials will need to be tested for clinical efficacy on malodorous wounds of patients. Further work will include the development of multi-laminate films with improved functionality, with the lower surface to be made from a swelling polymer to improve the potential exudate handling qualities and give greater control of the moisture content of a healing wound.

\section{Conclusions}

The addition of activated carbon to a plasticised agarose film increased the adsorption of volatile sulphur compounds both from a liquid phase and vapour phase. The rate of water vapour transmission across the films was within accepted standard limits for wound dressings. The presented data suggested that such films are good candidates for the adsorption of malodorous compounds released from chronic wounds, including volatile gases.

\section{Acknowledgements}

Thanks to Dr Guy Standen, University of Brighton, for light microscopy images. This project has received funding from the Interreg 2 Seas programme 2014-2020 co-funded by the European Regional Development Fund under subsidy contract number DERMA 2SO1-027 and the Ministry of Education and Science of the Republic of Kazakhstan, project Carbon-polymer dressings for the treatment of chronic ulcers. $\mathrm{MI}$ and TN acknowledge financial support of the Royal Academy of Engineering, grant IAPP $\backslash 1516 \backslash 12$ 'Wound dressings for malodorous chronic ulcers'. Graphical abstract assistance from the University of Portsmouth, Media Production Centre. 


\section{Conflict of interest}

The authors declare that they have no conflict of interest. 


\section{References}

1. Boateng JS, Matthews KH, Stevens HN, Eccleston GM. Wound healing dressings and drug delivery systems: a review. Journal of pharmaceutical sciences. 2008;97(8):2892-923. doi:10.1002/jps.21210. 2. Adderley UJ, Holt IG. Topical agents and dressings for fungating wounds. The Cochrane database of systematic reviews. 2014(5):Cd003948. doi:10.1002/14651858.CD003948.pub3.

3. Hyder ON, Soukas PA. Chronic Venous Insufficiency: Novel Management Strategies for an Underdiagnosed Disease Process. Rhode Island medical journal (2013). 2017;100(5):37-9.

4. Karki DB, Yadava SK, Pant S, Thusa N, Dangol E, Ghimire S. Prevalence of Sensory Neuropathy in Type 2 Diabetes Mellitus and Its Correlation with Duration of Disease. Kathmandu University medical journal (KUMJ). 2016;14(54):120-4.

5. Shanmugam VK, Angra D, Rahimi H, McNish S. Vasculitic and autoimmune wounds. Journal of vascular surgery Venous and lymphatic disorders. 2017;5(2):280-92. doi:10.1016/j.jvsv.2016.09.006.

6. Shoham N, Gefen A. Deformations, mechanical strains and stresses across the different hierarchical scales in weight-bearing soft tissues. Journal of tissue viability. 2012;21(2):39-46. doi:10.1016/j.jtv.2012.03.001.

7. Mahalingam S, Gao L, Nageshwaran S, Vickers C, Bottomley T, Grewal P. Improving pressure ulcer risk assessment and management using the Waterlow scale at a London teaching hospital. Journal of wound care. 2014;23(12):613-22. doi:10.12968/jowc.2014.23.12.613.

8. Labows JN, McGinley KJ, Webster GF, Leyden JJ. Headspace analysis of volatile metabolites of Pseudomonas aeruginosa and related species by gas chromatography-mass spectrometry. J Clin Microbiol. 1980;12(4):521-6.

9. Cox CD, Parker J. Use of 2-aminoacetophenone production in identification of Pseudomonas aeruginosa. J Clin Microbiol. 1979;9(4):479-84.

10. Parry AD, Chadwick PR, Simon D, Oppenheim B, McCollum CN. Leg ulcer odour detection identifies beta-haemolytic streptococcal infection. Journal of wound care. 1995;4(9):404-6.

11. Scholler C, Molin S, Wilkins K. Volatile metabolites from some gram-negative bacteria.

Chemosphere. 1997;35(7):1487-95.

12. Dini F, Capuano R, Strand T, Ek AC, Lindgren M, Paolesse R et al. Volatile emissions from compressed tissue. PLoS One. 2013;8(7):e69271. doi:10.1371/journal.pone.0069271.

13. Holloway S. Recognising and treating the causes of chronic malodorous wounds. Prof Nurse. 2004;19(7):380-4.

14. Hareendran A, Bradbury A, Budd J, Geroulakos G, Hobbs R, Kenkre J et al. Measuring the impact of venous leg ulcers on quality of life. J Wound Care. 2005;14(2):53-7.

doi:10.12968/jowc.2005.14.2.26732.

15. Maddox D. Effects of venous leg ulceration on patients' quality of life. Nursing standard (Royal College of Nursing (Great Britain) : 1987). 2012;26(38):42-9. doi:10.7748/ns2012.05.26.38.42.c9111. 16. Shamsuri AA, Daik R. Plasticizing effect of choline chloride/urea eutectic-based ionic liquid on physicochemical properties of agarose films. Bioresources. 2012;7(4):4760-75.

17. S. V. Mikhalovsky VMGK, V. V. Turov, R. Leboda, W. R. Betz. Investigation of Structural and Adsorptive Characteristics of Various Carbons. Adsorption. 2005;11(Supplement 1):657-62. doi:10.1007/s10450-005-6002-8.

18. Mohamed F, Kim J, Huang R, Nu HT, Lorenzo V. Efficient control of odors and VOC emissions via activated carbon technology. Water environment research : a research publication of the Water Environment Federation. 2014;86(7):594-605.

19. Akhmetova A, Saliev T, Allan IU, Illsley MJ, Nurgozhin T, Mikhalovsky S. A Comprehensive Review of Topical Odor-Controlling Treatment Options for Chronic Wounds. Journal of wound, ostomy, and continence nursing : official publication of The Wound, Ostomy and Continence Nurses Society. 2016;43(6):598-609. doi:10.1097/won.0000000000000273.

20. Wang F, Gao B, Yue Q, Bu F, Shen X. Effects of ozonation, powdered activated carbon adsorption, and coagulation on the removal of disinfection by-product precursors in reservoir water.

Environmental science and pollution research international. 2017. doi:10.1007/s11356-017-9451-1. 
21. Lipman RD, van Bavel D. Odor Absorbing Hydrocolloid Dressings for Direct Wound Contact. Wounds. 2007;19(5):138-46.

22. Beckett R, Coombs TJ, Frost MR, McLeish J, Thompson K. Charcoal cloth and malodorous wounds. Lancet (London, England). 1980;2(8194):594.

23. Naka K, Watarai S, Tana, Inoue K, Kodama Y, Oguma K et al. Adsorption effect of activated charcoal on enterohemorrhagic Escherichia coli. The Journal of veterinary medical science. 2001;63(3):281-5.

24. Lu S, Ji Y, Buekens A, Ma Z, Jin Y, Li X et al. Activated carbon treatment of municipal solid waste incineration flue gas. Waste management \& research : the journal of the International Solid Wastes and Public Cleansing Association, ISWA. 2013;31(2):169-77. doi:10.1177/0734242×12462282.

25. Vega E, Sanchez-Polo M, Gonzalez-Olmos R, Martin MJ. Adsorption of odorous sulfur compounds onto activated carbons modified by gamma irradiation. J Colloid Interface Sci. 2015;457:78-85. doi:10.1016/j.jcis.2015.06.037.

26. NICE. Odour absorbent dressings. National Institute for Health and Care Excellence 2017. 27. Wu P, Nelson EA, Reid WH, Ruckley CV, Gaylor JD. Water vapour transmission rates in burns and chronic leg ulcers: influence of wound dressings and comparison with in vitro evaluation. Biomaterials. 1996;17(14):1373-7.

28. Wu P, Fisher AC, Foo PP, Queen D, Gaylor JD. In vitro assessment of water vapour transmission of synthetic wound dressings. Biomaterials. 1995;16(3):171-5. 